\title{
Substitute for the Breast Milk (Sale, Distribution and Control) Act 2049: Revisited
}

\author{
Shrestha $\mathbf{M}^{1}$, Basnet $\mathrm{S}^{2}$, Shrestha $\mathrm{PS}^{3}$
}

${ }^{1}$ Dr. Merina Shrestha, ${ }^{2}$ Prof. Srijana Basnet, ${ }^{3}$ Prof. Prakash Sunder Shrestha. All from Nepal Breast feeding Promotion Forum (NEBPROF), Kathmandu, Nepal.

\section{Address for correspondence:}

Dr. Merina Shrestha

Breast feeding Promotion Forum (NEBTPROF)

Kathmandu, Nepal.

E-mail: drmerinashrestha@gmail.com

\section{How to cite}

Shrestha M, Basnet S, Shrestha PS. Substitute for the Breast Milk (Sale, Distribution and Control) Act 2049: Revisited. J Nepal Paediatr Soc 2016;36(3):219-221.

doi: http://dx.doi.org/10.3126/jnps.v36i3.17114

This work is licensed under a Creative Commons Attribution 3.0 License.
$T$ here is a National strategy of infant and young child feeding which includes exclusively breastfeeding till six months, timely start of complementary feeding and continuing breastfeeding till two years and beyond. However very few of us are aware of Breast Milk Substitute Act (BMS) in the country. Here we have tried to summarize the Act which would help us to be aware of our law and protect and promote breastfeeding.

BMS Act 2049 was published by Government of Nepal in 2049. This Act focuses mainly to control the sale and distribution of Breast Milk Substitute (BMS). BMS means an edible product that is sold and distributed to partially or fully substitute the Breast Milk. In Nepal this Act covers till one year of age. After the formation of Act in 2049, there has not been any amendment. With increased marketing policies for BMS and low awareness about the law, its high time the Act is revised, amended and more awareness programs to be initiated.

The main objective of this Act is to patronize and promote breastfeeding.For the implementation of the Act, government has appointed Breast Feeding Protection and Promotion Committee (BPPC)which is chaired by the Secretary of Health Ministry.Ministry of Health with consultation with BPPC can give permission to publicize the information and educational materials about infant food. The Act has clear guidelines for manufacturers and distributors along with health care professionals as well.

\section{Guidelines for Health care professionals:}

To promote breastfeeding, stakeholders like Nepal Pediatric Society (NEPAS), Nepal Breastfeeding Promotion Forum (NEBPROF), Perinatal Societyof Nepal (PESON), Child Health Division(CHD) and other organization working for wellbeing of children should take appropriate measures to promote the principles of the Act by informing about the responsibilities.

\section{Health workers}

1. Should act together to protect, promote and encourage breastfeeding.

2. Should not do anything to impede the beginning and expansion of breastfeeding.

3. Should not accept any financial or material gifts from manufacturers or distributors of BMS.

4. Should not provide samples of any product to anyone.

J. Nepal Paediatr. Soc. 
5. Should not promote BMS product in any manner.

6. Should report about it in writing to his/her higher authorities if a company seeks to give any gift or other monetary benefits to him/her

\section{Guidelines for the manufacturers}

Written, audio or visual information and educational materials about infant food must provide clear information on following points:

a) Benefits of Breast Feeding.

b) Production and maintenance of Breast milk including mother's nutrition.

c) Negative effects of bottle feeding or untimely complementary feed on Breast Feeding.

d) Problem in initiation of Breast Feeding after an infant is fed by bottle.

e) Regarding complementary food or BMS following information and the educational materials should be clearly mentioned:

1. Appropriate and correct use of substitute for Breast milk.

2. Cost involved in feeding the infant with substitute breast milk in comparison to Breast Feeding.

3. Bad effects on health by feeding incorrectlyprepared BMS and inappropriate food and bottle feeding

4. Method of feeding with bowl and spoon

5. Method of preparing complementary food at home

While informing there should not be any statement or any photograph that discourages the breast-feeding or promotes the habit of bottle-feeding.

\section{Manufacturers SHOULD NOT}

1. Advertise to promote any product and should not make believe that bottlefeeding is equal to or better thanbreastfeeding.

2. Advertise by any publication or by television, radio, film video or telephone, symbol, billboard or exhibition of the materials or photographs.

3. Introduce the product to any person by using printed materials including name of thepropriety product,logo, graphics or books,pamphlets or posters containing images

\section{Distributors of BMS SHOULD NOT:}

1. Make available theproduct at lower price than the retail price

2. Donate to health care agency or other organizationexcept when seeks grant in prescribed manner and such demand accepted by the committee.

3. Make contact with general public in the premises of health care agency to promote the substitute.

4. Donate any equipment or material to health care agency without taking permission from the committee.

5. Give any gift or provide monetary or other benefits to health workers

6. Give scholarship or research grant or organize seminar or meeting unless approved by the committee.

Following guidelines should be followed while labeling the product:

1. Local and easily understandable language should be used.

2. Provide necessary information on method of itsuse and it must not discourage breastfeeding.

3. There should not be any photo, map or images on the label of the product or container except graphic that explains the method of preparing it.

4. Name and address of manufacturer and if possible distributors should be on the label.

5. Irremovable label of the container should have following

- Important notice or similar

- Statement that the breastmilk is best for the baby

- Regarding need and method of use, and statement that it should not ne used without advice from health worker

- Easily comprehensible and appropriate direction and graphics to prepare the baby food

- Quantity of the substitute or any other milk product of breast milk for each month should be mentioned.

6. Words like humanized or similar words should not be used. 


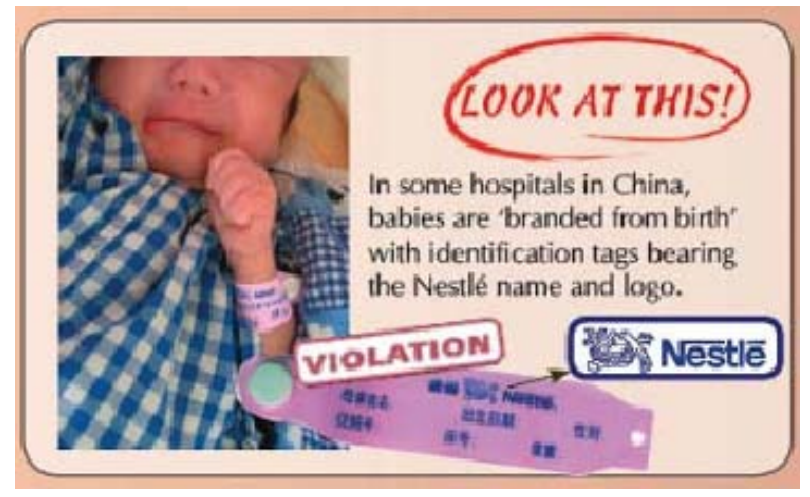

Picture: Brand Promotion

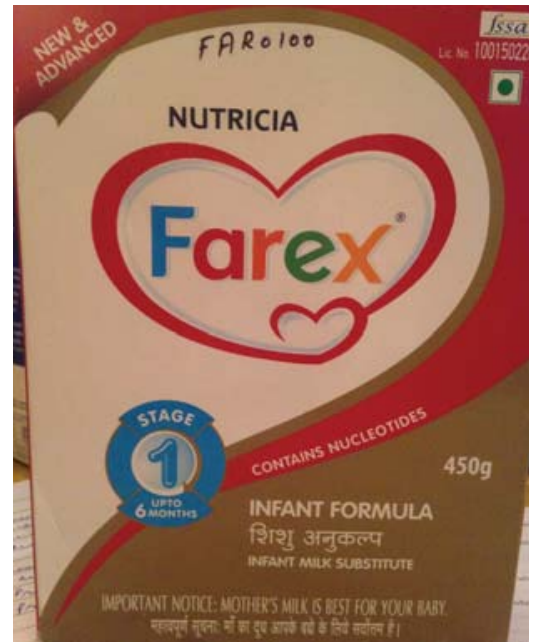

Claims on the label

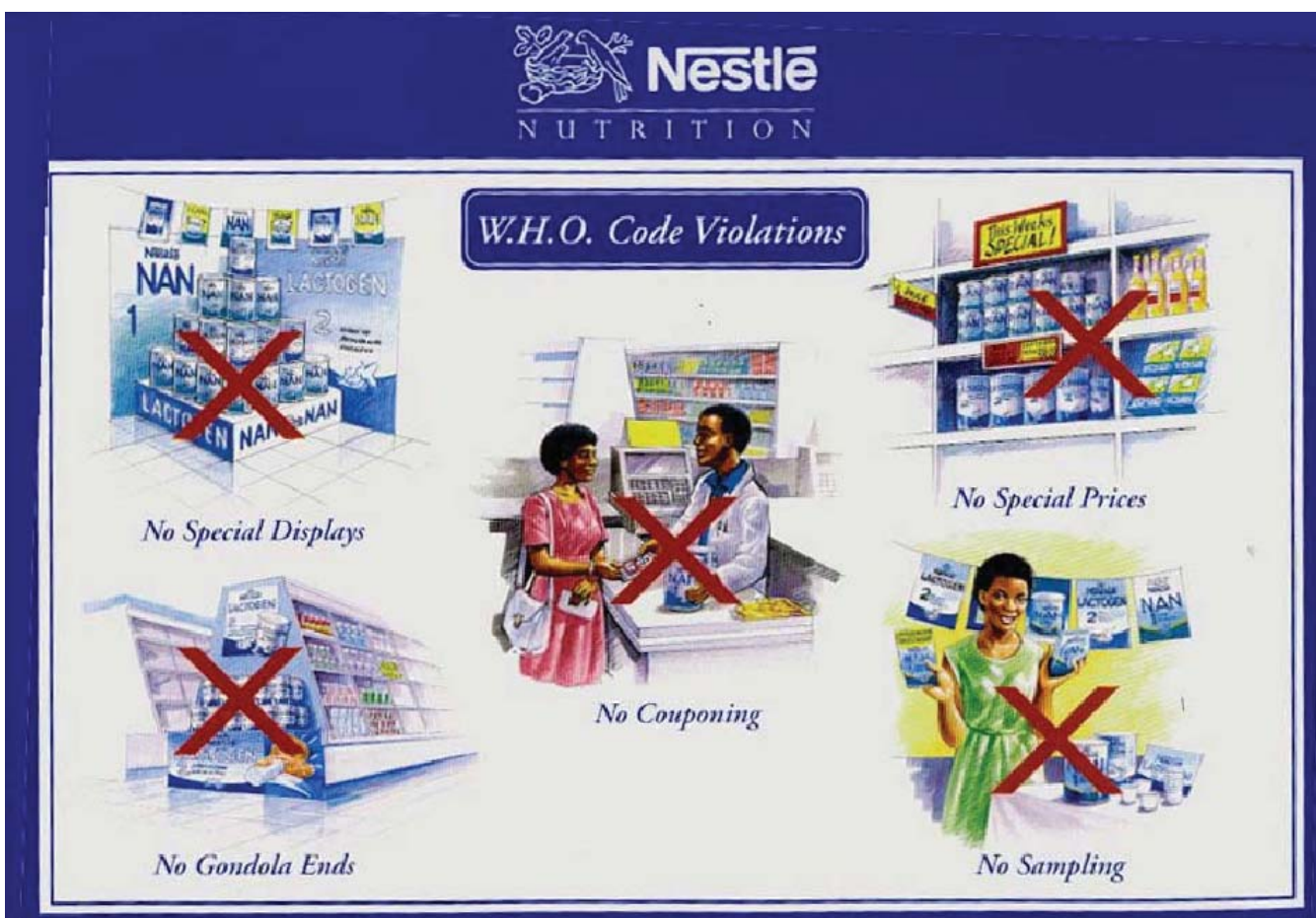

The most trusted name in nutrition for 130 years.

Few examples of violation of Breast Milk Substitute Act: Adapted from International Code of Breast Milk Substitute(ICDC) 